\title{
EDUCAÇÃO KAINGANG: \\ O "FORMAL" E O "INFORMAL" NA ESCOLA DA ALDEIA EM SÃO LEOPOLDO, RS, BRASIL
}

\author{
EDUCATION KAINGANG: \\ THE "FORMAL" AND "INFORMAL" IN THE \\ VILLAGE SCHOOL IN SAO LEOPOLDO, RS, BRAZIL
}

Diego Fernandes Dias Severo*

RESUMO: Neste trabalho, por meio da metodologia etnográfica, abordar-se-á o significado da educação para o grupo Kaingang na cidade de São Leopoldo. Inicialmente, buscou-se literatura sobre a temática, pertinentes a aspectos da organização social desta população, processos socioculturais, educacionais, assim como referências sobre a relação desta população e as imposições da escola no século XX. Em seguida, apresentaremos o processo de materialização da aldeia Põr Fi Ga e a batalha para a escola Kaingang. Com isso, analisaremos o significado da escola na aldeia para professores e lideranças indígenas, contrastando o mesmo com o discurso da equipe diretiva da escola "regular" - cuja escola da aldeia é vinculada. Conclui-se que, apesar da escola na aldeia ser vinculada e não totalmente independente, as práticas escolares postas pelos professores e comunidade carregam os processos educativos não formais para o interior da instituição.

Palavras-chave: educação indígena, escola, indígena, Kaingang, São Leopoldo.

\footnotetext{
* Licenciado em Ciências Sociais pela Universidade do Vale do Rio dos Sinos, Mestrando do Programa de Pós-Graduação em Ciências Sociais pela Universidade Federal de Santa Maria - UFSM; Santa Maria, RS, Brasil; e-mail: diegofdias@gmail.com
} 
ABSTRACT: In this paperwork, through ethnographic methodology, the meaning of the education to São Leopoldo's Kaingang group will be handled. At first instance, a search along previously knew literature about the subject was made, pointing relevant aspects of the social organization of this population and their social, educational and cultural processes, as long as references about the relation among this group and the 20th century's school impositions. After that, we will introduce the Põr Fi Ga materialization process and the battle for a Kaingang school. Then, we will analyze the meaning of the school to teachers and indigenous leadership, contrasting it with the directive team's speech from the "regular" school - which village school is connected. It follows that, despite the school in the village be connected and not totally independent, school practices made by teachers and community carry informal educational processes into the institution.

Keywords: indigenous education, school, indigenous, Kaingang, São Leopoldo.

\section{INTRODUÇÃO}

O presente trabalho é resultado de pesquisas realizadas durante o trabalho de conclusão do autor no curso de Licenciatura em Ciências Sociais, na Universidade do Vale do Rio dos Sinos, durante os anos de 2010 e 2011 (Severo, 2011). Ainda, engloba parte dos resultados já encontrados durante pesquisas no curso de mestrado em Ciências Sociais pela Universidade Federal de Santa Maria.

$\mathrm{O}$ artigo discute questões educacionais entre os Kaingang, no município de São Leopoldo, na aldeia Por Fi Ga, trazendo relatos sobre a realidade da educação escolar no local. A escola, juridicamente, não é uma escola indígena, estando vinculada à outra instituição "regular" estadual. Os confrontos encontrados e demonstrados, aqui, pelos discursos dos kaingang e a direção da escola não demonstram um clima de tencionamento no plano da prática diária da escola. Ambos se respeitam e trabalham com a alteridade de formas diferentes. 
Em um primeiro momento, buscamos apresentar um pouco do povo kaingang, abordando questões relativas a seu pertencimento linguístico, organização social, costumes, regras de parentesco, etc. Logo após, abordaremos a história do grupo na cidade de São Leopoldo, durante o período de 1994 e 2011, contada a partir dos relatos dos indígenas, presentes desde o inicio, documentos contidos em processos do Ministério Público Federal - Novo Hamburgo e a versão da prefeitura, que não existe, simplesmente. Trazendo, também, como atualmente a aldeia está constituída, e seus cenários educativos (Brandão, 1995).

Após, trabalharemos com os dois discursos encontrados sobre a realidade escolar indígena em São Leopoldo - primeiramente, retomando e discutindo falas da direção da escola "regular", a qual a escola da aldeia está vinculada -, onde encontraremos dados que indicam o despreparo para o trabalho com comunidades indígenas, além de questões e visões estereotipadas a cerca dos "índios". Em seguida, mostramos o que foi apresentado na aldeia sobre sua educação, em que a escola se constitui não somente de uma instituição "de fora" do fog (não índio) para o índio. E, sim, um local onde o que mais se trabalha são questões relativas à sua cultura, suas histórias, sua língua, seu tempo, seu espaço. O tempo e a sabedoria kaingang dialogam com o tempo do ocidente, de maneira "informal" suprimindo datas, tais como o "descobrimento" do Brasil e o dia do índio, as trabalhando de outra forma, com outros objetivos.

Por fim, ciente de que o trabalho antropológico - especificamente, da antropologia da educação - não tem por finalidade propor ou revolucionar a realidade estudada, mas, sim, podemos e devemos apontar determinadas questões que aparecem nas pesquisas e que, de uma maneira ou de outra, podem informar aspectos problemáticos encontrados e as autoridades responsáveis podem agir mais eficazmente onde falham as políticas públicas (Rockwell, 2009).

Brevemente, aqui, vejo como necessário uma explicação acerca do local de onde estamos falando, quase como um exercício de observação participante, descrevendo as coisas e pessoas como estão dispostas, o que fazem, como interagem, sua circularidade, os adultos, as crianças, os velhos que tipo de relações sociais estabelecem. 
A aldeia kaingang surpreende as autoridades que desconhecem a história dos indígenas, por estar situada no urbano - ali onde sua Cultura tem de ser constantemente inventada (Wagner, 2010), para que siga a imagem produzida no não índio. Um local alto da cidade de São Leopoldo, com algumas árvores, uma grande figueira na área central e em frente à estrada da aldeia.

Entrando, visualizamos muitas casas parecidas, todas de concreto - uma delas, mais antiga, pertencia ao dono anterior do local -, longe do imaginário ocidental das "ocas". Atualmente, a aldeia tem cerca de 150 habitantes, 25 casas - e muitas crianças. Ao entrarmos, deparamo-nos com as rodas formadas pelos indígenas; ali, produzem seus artesanatos, sentados no chão, passando o chimarrão, lidando com facas nas taquaras e cipós que, aos poucos, viram um artesanato, geralmente cestos, posteriormente revendidos nas feiras ou de porta em porta. As crianças que participam da roda não ficam paradas, assistindo: elas circulam pelos muitos cantos da aldeia, voltam para o encontro com seus pais e brincam com as facas, tentando imitar o movimento realizado de seus pais e parentes. Construindo e destruindo os artesanatos, a criança aprende. Nada se entende do que os índios falam, sempre dialogam em sua língua, o kaingang, nós somos os fog (não índios), por vezes fog kupri (não índio branco), o português só é utilizado para o contato comercial ou quando professores e pesquisadores frequentam a aldeia. Todos estranham as primeiras visitas de um fog, contudo, aos poucos nossa presença é acostumada, a alegria de contar suas histórias, de nos apresentar a sua Cultura, é gratificante.

Voltando às rodas de artesanato, elas são formadas por parentes ligados a um mesmo velho ancestral; assim, visualizamos a divisão da aldeia em famílias, os pequenos circulam nesses espaços, os adultos têm mais receio - somente contatam um não-parente quando muito necessário. A produção dos artesanatos é feita pelos parentes, dividindo as tarefas de lascar a taquara, pintar, secar, aparar as taquaras velhas para depois virarem pés de cestos. Nas rodas, colocam sua criatividade ao objeto, dividem esse saber com os próximos... Em geral, posteriormente, toda a aldeia já compreende a nova tecno- 
logia. Indagados sobre como apreenderam a fazer tal procedimento, afirmam que sabem fazer desde sempre. O que revela que tal prática não surge somente com o advento do ter que vender para sobreviver; os índios, hoje, com 50 anos ou mais, aprenderam cotidianamente com seus pais, o inconsciente rege a prática, tal como nos ensinou Lévi-Strauss (1970; 1967).

\section{OS ÍNDIOS KAINGANG?}

Os kaingang pertencem à matriz lingüística Macro Jê, família Jê, sendo o ramo mais diferenciado dentro desta família (Rodrigues, 1986 apud Belz, 2008). O grupo se concentra na Região Meridional do Brasil, em áreas parecidas no planalto de São Paulo, Paraná, Santa Catarina e parte das Missiones Argentinas (Becker, 1995; Freitas, 2005). Regiões que, segundo pesquisas arqueológicas recentes, indicam que há dois mil anos são habitadas por grupos ligados ao tronco Macro Jê, a família Jê Meridional (Franscisco, 2006).

Aspectos que caracterizam os Kaingang são o de se organizarem em metades exógamas, patrilinearidade e de uxorilocalidade. A organização dualista, que caracteriza os Kaingang, é definida por Lévi-Strauss:

"Este termo define um sistema no qual os membros da comunidade
- tribo ou aldeia- são distribuídos em duas divisões, que mantém
relações complexas, as quais vão da hostilidade declarada à inti-
midade mais estreita, e a que se acham habitualmente associadas
diversas formas de rivalidade e de cooperação. Frequentemente,
estas metades são exogâmicas, isto é, os homens de uma só podem
escolher esposas entre as mulheres da outra, e reciprocamente."
(Lévi-Strauss, 2009, p. 108)

Com essas características, os Kaingang se organizam em duas metades: Kamé e Kairu. Estas se opõem e se complementam (Veiga, 1994). Os Kairu são relacionados à marca redonda (rârôr), a um homem empreendedor e a posição Leste. Os Kamé são relaciona- 
dos à marca comprida (râtéi), ligados à resistência e à posição Oeste (Veiga, 1994).

As metades são relacionadas com a origem do grupo que, segundo relato colhido por Nimuendaju,

"Saíram em dois grupos, chefiados por dois irmãos por nome Kañerú e Kamé, sendo que aquele saiu primeiro. Cada um já trouxe em número de gente de ambos os sexos. Dizem que Kañerú e sua gente toda eram de corpo fino, peludo, pés pequenos, ligeiros tanto nos seus movimentos como nas suas resoluções, cheios de iniciativa, mas de pouca persistência. Kamé e os seus companheiros, ao contrário eram de corpo grosso, pés grandes, e vagarosos nos seus movimentos e resoluções" (Nimuendaju, 1913 apud Veiga, 1994, p. 59-60)

As metades são o alicerce da organização dos Kaingang. Em um casamento, a mulher Kaingang da metade Kairu deve se casar com um homem da metade oposta, ou seja, Kamé. O mesmo acontece se invertermos esta ordem. $\mathrm{O}$ uso da patrilinearidade é relacionado da seguinte forma: os filhos, de ambos os sexos, pertencem à metade de seu pai (Veiga, 1994). A explicação deste fato foi dada na Terra Indígena de Nonoai, para Salzano; "porque é o homem que faz o filho” (Salzano, 1960 apud Veiga, 1994, p. 87). Também, outro fato que evidencia a patrilinearidade é a nominação, nas áreas Kaingang que preservam essa tradição, tais como a de Xapecó, pesquisada por Juracilda Veiga (1994): o pai procura um dos velhos conhecedores dos nomes e pede para que ele nomine seu filho. Este, conhecendo a metade do pai, dará o nome à criança. No entanto, isso não acontece no mesmo dia, pois o conhecedor dos nomes terá que procurar os nomes disponíveis da metade do pai da criança (Veiga, 1994).

A uxorilocalidade, apesar da grande interferência da sociedade envolvente, quando um rapaz se casa, ele vai morar junto do sogro ou em casa próxima. Ele só se tornará líder do grupo familiar quando seu sogro falecer e ele se tornar sogro (Veiga, 1994). As mulheres são colocadas, de acordo com a literatura, como as detentoras das 
informações da aldeia, elas funcionam como "amplificadoras" dos anseios da comunidade. Elas, as mães (Ian), segundo Veiga (1994), têm uma grande importância para a preservação e transmissão dos valores e padrões culturais dos Kaingang.

A relação entre as metades e o mito de origem é quase evidente. Se unirmos o relato do mito de origem, acima transcrito de Nimuendaju, que fala dos Kaingang da metade Kairu como ligeiros e cheios de iniciativa e, os da metade Kamé, como mais resistentes, e a tradição da união preferencial de um Kaingang Kamé com um Kaingang Kairu, fica evidente que, se unirmos a mitologia com a regra do casamento, a família idealizada pela tradição Kaingang, deve ser, cheia de iniciativas, como o Kairu e resistente como o Kamé.

Atualmente, o uso das metades, em algumas comunidades Kaingang, não se faz mais presente, como apresentado nos trabalhos de Saldanha e Rocha (2010) e Amaral (2011), onde as denominações já foram esquecidas. No entanto, na comunidade Por Fi Ga, de São Leopoldo/RS, a denominação e indicação dos indígenas com suas metades é muito forte e atual. Lideranças e professores enfatizam, em reuniões e exposições em aulas, o que "pode" e o que "não pode" dar em casamento. Com brincadeiras em sala de aula, os professores apontam os alunos (as) que podem se casar, e aqueles que, pelas metades serem a mesma, não podem.

O uso da referencia cosmológica de organização em metades é atribuído ao próprio conhecimento necessário para "ser" índio ou não na comunidade, assim como a utilização da língua. Lideranças, professores, agente de saúde e demais autoridades indígenas enfatizam que para que tenham legitimidades diante da comunidade, eles, no berço de sua família, têm que honrar e se esforçar para seguir a tradição, no caso a regra dos casamentos.

\section{A COMUNIDADE KAINGANG POR FI GA, E UMA BREVE HISTÓRIA DO GRUPO EM SÃO LEOPOLDO}

No município de São Leopoldo, duas versões distintas sobre a chegada dos kaingang circulam no imaginário da população e 
mesmo em instituições governamentais, não governamentais e universidades. Aqui, relataremos a história expressada pelos indígenas, relatadas por meio de entrevistas e conversas informais no percurso da etnografia realizada durante a pesquisa.

Os indígenas chegaram recentemente na cidade de São Leopoldo, no ano de 1994, ficando acampados nas intermediações da rodoviária municipal. Ali, trabalhavam com seus artesanatos, em construções ao entorno, como a ampliação da rodoviária, diversos calçamentos, obras em residências particulares etc. Chegaram à cidade, neste primeiro momento, cerca de cinco famílias, vindas da área indígena de Nonoai. Vieram, pois, anteriormente, muito vinham vender, alegando que o lugar "é bom para vender", da mesma forma que Amaral (2011) encontrou relatos entre os Kaingang em Santa Maria/RS.

Habituados a circularem entre os municípios aos arredores, as famílias circulavam nas cidades do Vale dos Sinos, vendendo seus colares, cestos e demais artesanatos. Após algumas reclamações de vizinhos, os indígenas se mudaram para outros lugares na cidade de São Leopoldo. Nesse primeiro momento, os indígenas não reivindicavam área para permanecerem, passando, dessa forma, invisíveis para agentes municipais, até o ano de 2002. No decorrer do período, entre 1994 e 2002, muitas famílias foram se agregando aos acampamentos; as motivações para a saída das áreas são muitas. Em relato, o segundo cacique do acampamento, que posteriormente "liderou" o grupamento para a aldeia Por Fi Ga, fala algumas motivações para a troca de município:

“[...] que nóis nas áreas por que o tempo melhor era os tempos atrás, como a vivencia tempos atrás era muito bom, quando nóis tinha as matas nativa, nós tinha caça, bastante fruto pra coleta, pinhão, mel puro e pescaria tinha a vontade, caça tinha a vontade também pra sobreviver, tu não precisava ira atrás tu tinha, tu tinha como viver dentro da sua aldeia, com suas próprias caças né, e como e hoje não existe mais lá, como eu disse sabe o índio não é agricultor, o índio é preservador da natureza, aonde que ele veve, é da própria natureza 
que ele veve. E agora, por que a terra bem dizer não é nossa, nós tamo só preservando, a terra é, a terra, é terra do governo federal nós não podemo fazer nada em cima, se fosse teu tu podia vender um pedaço de terra, fazer um financiamento, fazer empréstimo no banco pra tu tocar teu trabalho, teus serviços na agricultura, mas nem isso tu não tem, tu não tem acesso pra isso, assim sem a ordem da Funai, sem a ordem deles tu não faz isso aí, então como não tem como o índio viver lá dentro, então tem uns índios que saíram, que nem saímo de lá por isso aí né, vender nosso artesanato para sobreviver é onde que nóis encontremo, aonde que nóis tamo agora né, procuramo nossos direito..."1

O relato indica que a principal motivação é a sobrevivência do grupo, que, nas áreas, pelo relato, é precária. Outros relatos de indígenas apontam, assim como etnografias acadêmicas realizadas entre os kaingang, para a forte existência do faccionalismo, reunião de pessoas em torno da liderança, formando grupos de indígenas pró e contra, o que ocasiona laços e cortes nas relações comunitárias - como distribuição de terras para plantio, ascensão a empregos públicos e privados dentro das áreas, entre outros. Fato que não acontece somente na atualidade; Ítala Becker (1995) fala a respeito do grande conflito dos caciques Braga e Doble, onde grupamentos de kaingang se formavam alianças com um ou outro cacique, ou até mesmo com nenhum, formando novas aldeias em lugares distantes. O mesmo parece acontecer na atualidade entre os kaingang no Rio Grande do Sul, tendo em vista os inúmeros acampamentos kaingang formados nos Estados. Eles apontam para dois aspectos importantes: o retorno ás áreas de ocupação kaingang e para a sempre atual forma política de guiar a circulação dos indígenas, vista preliminarmente pela relação de parentesco.

No ano de 2001, os kaingang estavam acampados embaixo de um viaduto da BR-116, logo em frente ao Marco Zero da colonização alemã. Segundo relatos, agentes da prefeitura, "preocupados" com as crianças indígenas, ofereceram, em meados do mês de julho - mês

${ }^{1}$ Relato obtido pelo autor em 19 jul. 2012. 
em que ocorre a principal festa do município "São Leopoldo Fest" -, a opção de os indígenas se mudarem para a rua São Domingos. Após olharem e acordarem com a mudança, os kaingang se deslocaram no dia seguinte. Após um período no local, começaram a construir algumas casas de madeira - antes, a moradia consistia de barracos de lona - e outros indígenas iam chegando... Sobretudo, parentes vindos das áreas indígenas do norte do estado do Rio Grande do Sul.

Em 2002, agentes municipais "avisaram" aos kaingang que não podiam construir casas no local, que era para permanecer somente com barracas, pois ali não era o local fixo para eles, que deveriam deixar o município. Neste período, começaram a entrar em contato com grupos de apoiadores do município, em geral ONG's e instituições religiosas, além de receberem visitas de pessoas ligadas às universidades que, por meios institucionais, relataram ao Ministério Público Federal - Novo Hamburgo a situação precária em que se encontravam os índios.

Aqui, começa a história relatada nas páginas do processo que se estende até o ano de 2009, e não será abordado aqui em sua totalidade por fugir da proposta apresentada. No entanto, as primeiras páginas apresentam uma situação, no mínimo, curiosa, para não parecer trágica: o MPF manda oficio à FUNAI, para irem até o local de acampamento dos kaingang em São Leopoldo e verificarem as condições dos indígenas. Se apresentarem-se conforme as denúncias, que essa encaminhe os indígenas para as áreas a que "pertencem". No decorrer das páginas, o discurso muda; o problema pode dever-se às sobreposições da legislação, onde o Estatuto do Índio, há muito ultrapassado pela Constituição de 1988, ainda não foi reformulado.

As páginas do processo instaurado pelo MPF apresentam todos os detalhes dos conflitos entres os kaingang e a prefeitura municipal. Interessante constatar que, após a intervenção do MPF, os indígenas escolheram uma pessoa para ser cacique do acampamento - o que até 2002 não existia - pela necessidade de uma autoridade para dialogar com a prefeitura e outros locais. Assim, o grupo escolheu duas pessoas: um para cacique, outro para vice, afim de que estes intercedessem nas vias institucionais. Além de colaboradores 
não índios, os kaingang buscaram, em outros locais, parentes experientes no processo de luta por território, pessoas que participaram do processo de conquista de área indígena em Porto Alegre se mudariam para São Leopoldo, assim como outras se somaram no grupamento, na medida em que foram criados empregos públicos, como os de professor, agente de saúde e outros.

Em 2003, ano que antecedia as eleições municipais, os indígenas sofrerão pressões para que saíssem da localidade - inclusive, suborno no valor de cinco mil reais ao, então, cacique da comunidade para que este levantasse acampamento. Com a negativa do grupo, as pressões contrárias foram muitas. Tomaram a decisão de apoiar determinado candidato, já conhecido dos indígenas, que, com a vitória, havia prometido viabilizar terra aos indígenas. Com a vitória, as coisas se tornaram mais acessíveis, mas a pressão não cessou. As coisas acontecem "com pressão", frase muito falada entre os kaingang, e com o espírito lotado de esperança, o grupo se manifestou trancando a rua, ameaçando funcionários da empresa elétrica que cortariam sua luz, utilizaram-se de imagens que sabem que os fog (não índios) têm sobre os "índios", e chamavam os jornais, onde expunham crianças dentro de baldes de água vazios, afirmando que tomariam água do rio dos Sinos, altamente poluído. Fatos que, certamente, colaboraram para a viabilização da área indígena que desde 2007 habitam.

Atualmente, a aldeia Por Fi Ga conta com 150 pessoas, entre adultos e crianças, uma escola indígena com dois professores kaingang moradores da comunidade e uma agente de saúde. A aldeia localiza-se no bairro Feitoria, na Estrada do Quilombo - escolhida pelas lideranças por ser um local, entre os oferecidos pela prefeitura, que mais se adequava as demandas da comunidade. Com árvores frutíferas, em uma área da cidade alta, com poucos vizinhos não índios. Em 2007, quando se mudaram, havia cerca de dezoito famílias.

O processo de mudança foi como parece ser sempre: tomado de inúmeras reivindicações. As casas foram construídas às pressas pelas famílias, pois os vendedores tinham desistido de vender e exigiam novo valor, o que não aconteceu, e a área foi adquirida pela 
prefeitura pelo valor inicialmente acertado. Até meados de 2009, a comunidade não possuía banheiros; fato pelo qual, novamente, o MPF intercedeu pelos direitos dos indígenas, junto à prefeitura municipal e às agências de saúde.

Demandas como a de educação foram viabilizadas por vias institucionais estaduais, que construíram uma escola provisória que, até hoje, é a mesma, e delegaram a uma escola estadual das proximidades a responsabilidade pela escola da aldeia. Desta maneira, professores e funcionários indígenas são lotados nessa escola "normal", tendo de seguir as normas e o currículo desta, para os níveis de ensino trabalhados na aldeia.

As casas, no primeiro momento, construídas pelos indígenas, foram, recentemente - nos anos de 2010 e 2011 -, reconstruídas por um convênio realizado entre a Caixa e a FUNAI, totalizando vinte e duas casas, com dois quartos, sala, cozinha e banheiro. Algo que, hoje, já se modificou, pois parece que os moldes das casas era idêntico em todas e não poderiam ser modificados. Devido ao grande número de pessoas em uma única família, muitos puxadinhos foram construídos, além de uma peça, geralmente nos fundos da casa, com não mais de dois metros quadrados, sem piso, onde é realizado o fogo de chão, mais visto nos períodos de inverno, cozinhando feijão e outros alimentos, assim como aquecendo as lascas de taquara que são, posteriormente, coloridas.

\section{A EDUCAÇÃO ESCOLAR KAINGANG: DOIS DISCURSOS EM TORNO DE UMA PRÁTICA}

Os dados aqui apresentados são fruto do trabalho de conclusão de curso em Ciências Sociais do autor em 2011, onde foram melhor e mais amplamente abordadas a relação e as disputas em torno da efetivação dos direitos constitucionais acerca da educação diferenciada para indígenas.

A escola funciona em dois turnos, manhã e tarde. O espaço físico desta se limita a uma sala de aproximadamente $36 \mathrm{~m}^{2}$ e uma pequena cozinha dentro da sala. Devido ao pouco espaço, e ao nú- 
mero de professores, as aulas da manhã comportam estudantes da $1^{\circ}, 2^{\circ}$ e $3^{\circ}$ anos e a turma da tarde é composta pelos $4^{\circ}$ e $5^{\circ}$ anos. Juridicamente, a escola não é uma "escola estadual indígena", sendo vinculada à outra instituição escolar próxima à aldeia, onde professores e funcionários estão legalmente lotados, e para onde vai a verba destinada para a escola da aldeia.

A falta de autonomia jurídica dificulta a regularidade e a construção de um plano pedagógico próprio da escola indígena, tendo que os professores devem se submeter às regras avaliativas e aos planos curriculares produzidos pela escola à qual estão vinculados. Currículo que somente é construído pelos professores não índios, desconhecedores da diferença indígena e mesmo de suas particularidades étnicas. Aqui, é importante evidenciar que, mesmo com a aldeia situando-se no espaço urbano, quando adentramos na aldeia, o rural salta aos olhos - o modo simples de viver, o andar descalço, o fogo de chão, o falar a língua indígena, o chimarrão... Assim, abordarei os dados colhidos no ano de 2011, relatos das duas realidades, dos dois lados, o dos professores indígenas e da liderança da comunidade, acrescentando as observações realizadas na escola da aldeia e dentro da comunidade, destacando momentos privilegiados, de datas comemorativas, como o dia do índio, onde mesmo com certo atraso conseguimos participar de momentos significantes, onde se revela a prática cultural viva e significada nas crianças kaingang, e um momento de grande aprendizado para esse recente pesquisador que navegou e agora está disposto a cada vez mais achar-se na etnologia.

Primeiramente, abordaremos o discurso da gestão da escola "regular", a qual a escola da aldeia está vinculada. Durante o percurso de pesquisa para o trabalho final de graduação, recorri algumas vezes a essa escola para melhor entender sua relação com a estrutura na aldeia. Dessa relação, constata-se o presente relato sobre as visitas da escola "regular" à aldeia:

"Muito pouco. Esporadicamente. É uma coisa que não nos dá prazer, foi uma coisa que colocaram para gente, e nós fazemos a nossa parte e deu. A gente não faz nada além disso. Se nó poderíamos fazer, não 
sei. Ninguém quer a gente não tem disponibilidade para isso, tanto é que tu pode vê, hoje da direção eu estou sozinha aqui. Então como é que tu ainda vai disponibilizar tempo para ir atender eles. Não tem como, eles até gostariam que agente fosse mais lá, mais ao mesmo tempo quando a gente vai. Eles se sentem meio constrangido, a gente já foi lá em algumas situações e parece assim que daí eles ficam meio que, não sei te explicar eles não recebem a gente com tanta naturalidade, que eles entram aqui na nossa escola, porque quando eles vem para assinar o ponto, eles assinam o ponto aqui. Então eles vem, eles entram assinam o ponto, eles conversam, se eles precisam pedir alguma coisa eles pedem. Quando eles precisam de alguma coisa da secretaria também eles chegam, eles entram, não é que eles são atendidos assim do lado de fora, não, como a comunidade, eles entram eles tem acesso aqui dentro bem tranqüilo, mas eles não nos dão esse acesso. Eu acho que assim, é próprio uma situação constrangedora, porque aqui eles tem tipo uma casa bonita, e a deles não é, eu tenho a impressão que eles se sentem assim, um pouco. Não sei te dizer isso é opinião minha, né.”2

O relato acima exposto nos apresenta problemas identificados em inúmeros trabalhos sobre a temática da educação escolar indígena, tais como o de Gabriela Novaro (2009), que mostra o despreparo de professores com a alteridade, um problema também encontrado nas escolas não índias, como apresenta Neusa Gusmão (1999).

A medida imposta à escola pela $2^{\mathrm{a}} \mathrm{CRE}$ - Coordenadoria Regional de Educação do Rio Grande do Sul, como demonstra o presente relato, mostra-nos como as políticas públicas para a educação escolar indígena estão pouco efetivamente posicionadas no plano educacional do Estado. A verticalização das ordens de ação nas políticas para a educação, além de prejudicar os interessados na causa, ou seja, os indígenas, apresenta problemas administrativos àqueles que os recebem. Consequentemente, mais uma vez, prejudica a educação diferenciada. Esse processo de gestão da escola na aldeia foi expresso da seguinte maneira:

${ }^{2}$ Entrevista realizada pelo autor em 15 de abril de 2011. 
"Foi à prefeitura que colocou, eles estavam lá, e era uma zona de risco né, uma beira de estrada. Daí a prefeitura colocou eles ali, e via $\mathrm{CRE}$ automaticamente eles vieram para nós, porque antes eles estudavam no Mario Quintana, eles não tinham a escola independente, eles estudavam todos lá na escola Mario Quintana, e a partir do momento em que eles vieram aqui acho que um ano, ou dois eles estudavam aqui também, aí depois que eles tiveram a escolinha deles lá. Isso foi via CRE né à gente não.”3

A verba que é destinada, de maneira diferenciada, para as escolas indígenas é repassada para a escola à qual a escola da aldeia "pertence". Qualquer reparo necessário - vidros quebrados, tábuas soltas, mesas velhas, cadeiras sem assento, quadro pequeno, luz deficiente no local, livros amontoados - tem de passar aos olhos da direção da escola, assim como a alimentação para a merenda escolar é comprada pelos não índios, além de inúmeros outros aspectos.

As condições precárias na escola da aldeia são solucionadas pela própria comunidade, que entende que essa é necessária para seu bem-estar, seu presente e seu futuro, tendo o entendimento que, internamente, as coisas acontecem segundo suas "resoluções" e decisões de como as aulas e as atividades da escola devem funcionar, afirmações encontradas no relato da gestão da escola "regular":

“[...] eles pedem o material a gente fornece o giz, a folha de oficio, a merenda, a classe essas coisas a gente vai dando conforme a necessidade deles. E eles é só um pavilhãozinho, é só uma escolinha. Até o ano passado, no inverno eles vieram pedir, mata junta que a escola tinha frestas, e tava frio e daí a gente comprou, não sei quantos metros de mata junta, os pregos. Eles arrumaram, fogão a gente deu. Quando eles não têm as coisas a gente providencia, sempre com um certo controle, porque a gente também não tem tanta verba disponível. Porque a partir do momento que a escola fosse deles, sozinhos a verba deles é muito maior. Como eles índios. Mas como aqui nós, a gente tem, eles têm a verba que a gente ganha por aluno é muito

${ }^{3}$ Entrevista realizada pelo autor em 15 de abril de 2011. 
pouco. [...] Eles arrumam, eles fazem. Até porque eu acho entre eles existe uma parceria, entre a própria aldeia né. Porque lá na verdade, quem manda lá é o cacique. Até na escola, o cacique manda. Daí eles. E eles fazem e eles são bem parceiros, porque eles pegaram, a gente mandou a mata junta, os pregos que eles queriam e depois foi lá eles arrumaram tudo direitinho."4

A parceria em torno das melhorias da escola é referenciada no relato junto com o mando, possivelmente autoritário em seu imaginário, da figura do "cacique", liderança da comunidade indígena. No entanto, no caso dos Kaingang que, historicamente, migram para lugares diferentes (BECKER, 1995) quando alguma medida do cacique não se adequa aos anseios do restante da comunidade, ou de um grupo de parentes, o cacique parece estar, como aponta Pierre Clastres (2004, p. 151),

"[...] sob vigilância da tribo: a sociedade cuida para não deixar o gosto do prestigio transformar-se em desejo de poder. Se o desejo de poder do chefe torna-se muito evidente, o procedimento empregado é simples: ele é abandonado ou mesmo morto. O espectro da divisão talvez assombre a sociedade primitiva, mas ela possui os meios de exorcizá-lo."

Os conflitos internos nos quais passaram os Kaingang, nos últimos anos, acerca do cacique, e a alternância no cargo, assim como a distribuição dos cargos de liderança de acordo com os grupamentos de famílias extensas presentes na aldeia Por Fi Ga, revelam que a tradicionalidade e coerência com os costumes devem ser os preceitos seguidos pelo cacique.

A escola segue os preceitos do cacique, logo, da comunidade, estabelecendo bom relacionamento com os processos tradicionais, costumes indígenas ancestrais kaingang que apontam para atributos como a fabricação de artesanatos, as visitas aos parentes residentes em áreas indígenas, deslocamento para o comércio familiar dos ar-

${ }^{4}$ Entrevista realizada pelo autor em 15 de abril de 2011. 
tesanatos, o uso frequente da língua kaingang em sala de aula, assim como em todos os lugares da aldeia.

O ambiente escolar na aldeia, como já apresentado, não muito diferente das demais casas dos indígenas, é entendido como um espaço de continuação do aprendizado. Ali, quem ensina não é um professor branco, nem alguém que nunca foi visto pelos estudantes, é a mesma pessoa que momentos antes da aula está com sua família lascando uma taquara, é o mesmo que, com os alunos, vai colher taquara ou cipó no mato. É um parente, não um estrangeiro, portanto um "tio".

Nas observações durante os dois turnos das aulas, esse foi o estranhamento mais impactante do ponto de vista de um estudante de licenciatura que sabe bem o porquê da separação de "tio" e de "professor" e os ditames pedagógicos dos termos para a educação escolar. Entendendo a escola em seu espaço físico, a aldeia, os professores sendo moradores da mesma e da mesma etnia, pensei, no primeiro momento, que a afirmação poderia vir pelo demasiado contato das crianças, estudantes indígenas, com os professores, mas a explicação parece ser outra - melhor ouvir o que o "tio" kaingang nos revela:

"É que na verdade pra nós não existe professor, na nossa linguagem não existe, mas esse ser inteligente é o respeitado desde parentes assim, ou desde mais velhos por isso que nós interpretamos o mais velho então o tio, ele tem um vivencia e um conhecimento para ensinar eu mais novo, vamos dizer né, então vai ser o tio. E é questão de organização né, a pessoa mais velha é o tio, o avô é o livro de história da comunidade então é por aí que a gente vai acolhendo as pessoas pela questão do respeito. Então ser tio é ser o segundo pai, que o segundo pai na escola é o professor, e o tio vem a ser o segundo pai. Então isso pra nós é aceito, porque também pelas marcas tribais né, muitas vezes os alunos chama a gente de irmão que tem a mesma marca minha, e muitas vezes de cunhado né que a menina que é da minha marca contrária ela é minha cunhada." 
$\mathrm{Na}$ sequencia desse depoimento, o professor comparou o ser chamado de "tio" nas escolas em que fez estágio curricular no curso de Pedagogia: surpreendeu-se com as professoras, quando as mesmas "xingaram" os alunos quando as chamam de "tia". Segundo sua interpretação, isso acontece por ela ver o aluno como uma "peste" e que, se fosse sobrinho dela, não seria daquele jeito e, sim, "comportado".

Em São Leopoldo, a comunidade Por Fi Ga Kaingang, como já apresentado anteriormente, está localizada em perímetro urbano, sendo este um entre os muitos motivos que os levaram para a cidade: o comércio de seus artesanatos.

Cotidianamente, inverno e verão, grandes e pequenos círculos onde roda o chimarrão são visíveis na aldeia, onde homens e mulheres, adultos e crianças fazem seus artesanatos - colares, cestos de cipó e taquara, casinhas de passarinho, entre outros objetos. Ali, adultos e crianças localizam-se em um cenário de aprendizagem (Brandão, 1995) em que os conhecimentos orais são transmitidos pelos parentes que formam a roda. Conhecimentos de trançado (Silva, 2008), de histórias indígenas, de remédios do "mato", de técnicas e táticas de venda (Amaral, 2011), de articulações políticas internas, além de discussões acerca de ideias educacionais, ideias que visam solucionar o problema dos “jovens hoje não serem mais índios”, pois os kaingang ponderam bastante e cobram-se determinadas características que visam suprir o que chamam de "índio puro", no mesmo sentido encontrado por Freitas (2005). Entre as características, estão: o falar a língua, conhecer sua história, seus parentes, sua metade, com quem pode casar, os remédios do "mato", saber fazer os artesanatos, etc. A escola que engloba professores de dois grupos influentes na aldeia, e de marcas diferentes, um Kamé e outro Kanhru, é um espaço de grandes elogios pelos indígenas mais velhos, no entanto, a "Cultura" Kaingang é muito mais do que isso, e o espaço da escola é pequeno para todas as atividades desta (Wagner, 2010).

A escola na aldeia e seu funcionamento adquirem, de acordo com as considerações do professor kaingang, um status informal dentro da instituição formalizada da escola. Apesar do currículo e a organização do calendário, elaborados pelos professores fog (não 
índios), na aldeia, os professores unem os dois conhecimentos, o tradicional e o ocidental de forma peculiar.

A língua kaingang é constantemente falada na aldeia Por Fi Ga: até o momento, não conheci algum indígena morador da aldeia que não fale sua língua. Essa particularidade do grupo residente em São Leopoldo apresenta um cenário de aprendizagem diferenciado, na medida em que muitos exemplos dados em sala de aula, na alfabetização da língua portuguesa, por exemplo, quando os alunos têm dúvidas quanto às frutas ou objetos dados nos exemplos, o professor menciona a palavra em kaingang, e o estudante faz a referência para o português. Indiretamente, a prática do professor no processo de aprendizagem sinaliza para a desejada interculturalidade em que seu cotidiano está diretamente ligado à questão dos conhecimentos (Paula, 1999).

A escola, quando adentra nas comunidades indígenas - no nosso caso, a seu pedido e livre manifestação -, leva conhecimentos e ideias pré-concebidas, o esforço para o cumprimento da legislação que admite a particularidade étnica, faz com que os interessados pela escola decidam quais e de que forma os conhecimentos, e quais conhecimentos devem ser trabalhados. Quais os conhecimentos necessários para atender a demanda dos Kaingang de São Leopoldo? O que querem da escola? Quais seus anseios? Essas respostas só podem ser dadas e devidamente entendidas em seu contexto sociocultural.

Articulando as duas formas de ciência, tradicional e ocidental, ciências que não tem o mesmo objetivo (Carneiro da Cunha, 2009), mas que dialogam dentro do universo escolar da aldeia. Professores com projetos pedagógicos milenares, ancestrais, fora do papel, reproduzindo e passando valores da sociedade em que vivem, a Kaingang. Um saber concreto, prático, sem formalização, tal como o ocidente o compreende, da aprendizagem inculcada na vivência, atingindo o inconsciente (Lévi-Strauss, 1970; 1967).

\section{CONSIDERAÇÕES FINAIS}

Como vimos ao longo do texto, a escola da aldeia Kaingang Por Fi Ga, em São Leopoldo, é uma instituição “tutelada” por outra 
instituição escolar. Medidas e imposições são impostas aos índios, todas de acordo com os planos educacionais do Estado do Rio Grande do Sul e, mesmo havendo legislação atualizada sobre a educação escolar indígena, onde rege que seja intercultural, diferenciada etc., parece que a legislação não chega ao chão da aldeia, institucionalmente, porém os indígenas fazem cumprir-se na prática - mesmo em condições materiais precárias, pois, como mencionado anteriormente, a estrutura da escola é pequena, com goteiras, tábuas soltas nas paredes, janelas quebradas, classes e cadeiras em mal estado de conservação, livros sem espaço físico adequado para acomodá-los e preservá-los.

Quanto à alimentação, a cozinha da escola é junto da sala de aula, onde a responsável circula entre os alunos com panelas e alimentos para seu preparo, assim como as compras de alimentos e, até mesmo, materiais da escola - atividades realizadas pela outra instituição, fornecendo, dessa maneira, comida e demais materiais, sem consultar aos índios.

No entanto, esses inúmeros "problemas" não causam grande dificuldade para o exercício das aulas na escola da aldeia. Reivindicações e deliberações de professores e lideranças da aldeia, a respeito das condições da escola, geralmente se dão diretamente com os responsáveis na Secretaria de Educação - RS. A experiência dos atuais professores indígenas mostram aos mesmos que tentar resolver essas questões estruturais com os diretores da escola não adianta em nada, pois enxergam que as mudanças estão sendo realizadas aos poucos; inúmeras mudanças tem caráter urgente, diálogos que devem ser feitos com quem pode resolver.

Como apresentado ao longo do texto, o calendário da escola na aldeia segue um ritmo próprio, são orquestrados de modo nativo, onde horários, conteúdos, dias de aula fora do ambiente da sala de aula e outros momentos são entendidos como educativos... Tal como o fazer do artesanato, a coleta de materiais, o comércio, visita a parentes etc. Portanto, a carga horária total da escola da aldeia não se fixa na sala de aula e, sim, em lugares de circularidade Kaingang, em outras aldeias, cidades etc. (SAHLINS, 1997). 
Dessas muitas variantes que se constatam observando o cotidiano da escola indígena, podemos concluir que os indígenas estão adequando a instituição escolar à sua realidade, conseguindo de maneira interessante realizar a desejada interculturalidade, articulando conhecimento ocidental, escolar, e tradicional, Kaingang. Observa-se, dessa maneira, que leis e planos nacionais e estaduais de ensino são importantes, mas, cumpridos com o esforço dos indígenas para concretização, faltam ações mais precisas nos contextos específicos das escolas indígenas, o diálogo entre os conhecimentos acontece e é proporcionado por atores indígenas. $\mathrm{O}$ entendimento de que educação diferenciada é somente a língua indígena ainda rege o pensamento de alguns agentes estatais, principalmente aqueles que atuam na ponta das políticas diferenciadas. Ações e procedimentos radicalmente não instituídos devem ser incorporados na instituição escolar indígena, de modo juridicamente aceito, para assim se concluir, enfim, um passo importante sobre o reconhecimento e aceite dessas práticas.

\section{REFERÊNCIAS}

BECKER, Ítala Irene Basile. O indio Kaingáng no Rio Grande do Sul. São Leopoldo: Ed. UNISINOS, 1995.

BELZ, Karina Cristiane. Educação Escolar Kaingang: do discurso oficial às práticas efetivas. 2008. Dissertação (Mestrado em Educação) Programa de Pós-graduação em Educação, Universidade Federal de Santa Catarina, Florianópolis, 189 p.

BRANDÃO, Carlos Rodrigues. O que é educação? São Paulo: Brasiliense, 1995.

CARNEIRO DA CUNHA, Manuela. Cultura com aspas e outros ensaios. São Paulo: Cosac Naify, 2009.

CLASTRES, Pierre. Arqueologia da violência. São Paulo: Cosac Naify, 2004.

FRANCISCO, Aline Ramos. Selvagens e intrusos em seu próprio território: a expropriação do território Jê no sul do Brasil (1808-1875). 2006. Dissertação (Mestrado em História) Programa de Pós-graduação 
em História, Universidade do Vale do Rio dos Sinos, São Leopoldo, $212 \mathrm{p}$.

FREITAS, Ana Elisa de Castro. Mrur Jykre: a cultura do cipó territorialidades Kaingang na bacia do Guaíba. 2005. Tese (Doutorado em Antropologia Social) Programa de Pós-graduação em Antropologia Social, Universidade Federal do Rio Grande do Sul, Porto Alegre, 230 p.

GUSMÃO, Neusa Maria Mendes de. Linguagem, cultura e alteridade: imagens do outro. Cadernos de Pesquisa, n. 107, pp. 41-78, jul. 1999.

LÉVI-STRAUSS, Claude. Antropologia Estrutural. Tradução de Chaim Samuel Katz e Eginardo Pires. Rio de Janeiro: Tempo Brasileiro, 1967.

. As estruturas elementares do parentesco. Tradução de Mariano Ferreira. 5. Ed. Petrópolis: Vozes, 2009.

. O pensamento selvagem. Tradução de Maria Celeste da Costa e Souza e Almir de Oliveira Aguiar. São Paulo: Editora Nacional; Editora da USP, 1970.

NOVARO, Gabriela. Palabras desoidas - palabras traducidas: voces y silencios de niños bolivianos en escuelas de Buenos Aires. Revista Educação. Santa Maria: UFSM, Vol.34, n.1, pp.01-12, 2009.

PAULA, Eunice Dias de. A interculturalidade no cotidiano de uma escola indígena. Cadernos Cedes. Campinas, Ano XIX, no .49, pp. 76-91, 1999.

ROCHA, Chintia Creatini da; SALDANHA, José Rodrigo. O parentesco como mote de reflexão acerca dos processos de alianças e cisões Kaingang. Trabalho apresentado na $27^{a}$ Reunião Brasileira de Antropologia. Belém, Pará, 2010.

ROCKWELL, Elsie. La experiencia etnográfica: historia y cultura em los procesos educativos. Buenos Aires: Paidós, 2009.

SANTOS, Daiane Amaral dos. Práticas e táticas de um "fazer econômico": Os Kaingang do setor Pedra Lisa - TI Guarita. 2011. Dissertação (Mestrado em Ciências Sociais) Programa de Pós-Graduação em Ciências Sociais, Universidade Federal de Santa Maria, Centro de Ciências Sociais e Humanas, Santa Maria, 122 p.

SEVERO, Diego Fernandes Dias. Educação Indígenas em São Leopoldo: 
processos educativos formais e não formais entre os índios Kaingang. 2011. Trabalho de Conclusão de Curso (Licenciatura em Ciências Sociais) Curso de Ciências Sociais, Universidade do Vale do Rio dos Sinos, São Leopoldo, 107 p.

SILVA, Sergio Baptista da. Contato interétnico e dinâmica sociocultural: os casos guarani e kaingang no Rio Grande do Sul. In: BERGAMASCHI, Maria Aparecida (Org.). Povos Indigenas \& educação. Porto Alegre: Mediação, 2008.

VEIGA, Juracilda. Organização social e cosmovisão Kaingang: uma introdução ao parentesco, casamento e nominação em uma sociedade Jê Meridional. 1994. Dissertação (Mestrado em Antropologia Social) Programa de Pós-graduação em Antropologia Social, Universidade Estadual de Campinas, Campinas, 242 p.

WAGNER, Roy. A invenção da cultura. São Paulo: Cosac Naify, 2010.

Recebido:06/09/2012

Aprovado:22/05/2013 